\title{
Reasons against referral to the psychiatrist
}

\author{
Alex G. Mezey \\ M.D., F.R.C.P.(Edin.), D.P.M. \\ JOHN M. KELLETT \\ M.A., M.B., M.R.C.P., D.P.M. \\ Department of Psychological Medicine, North Middlesex Hospital, London, N.18
}

\begin{abstract}
Summary
Consultants practising clinical specialties other than psychiatry in six general hospitals were asked by questionnaire about reasons which might prevent the referral of patients to a psychiatrist. The purpose of the enquiry was to find out the causes of the discrepancy between the prevalence of psychiatric disorder among medical and surgical patients and the low rate of referral.

Forty-five per cent of the consultants were influenced by the patient's dislike of referral; there was also evidence of marked dissatisfaction with existing psychiatric services at certain hospitals, felt chiefly by the younger consultants. Part-time consultants gave more reasons for non-referral, but there was no significant difference between medical and surgical specialties despite reported variations in referral practice.
\end{abstract}

It is concluded that general hospital psychiatric units have a role to play in improving the relationship between psychiatrists and other specialties so that referral practice can meet the needs of the patient.

\section{Introduction}

Several surveys have shown a discrepancy between the incidence of psychiatric disorder in patients attending non-psychiatric departments of general hospitals, and the rate of referral of these patients to the psychiatrist. Generally high but widely differing estimates of psychiatric morbidity (Table 1) have been obtained according to the criteria used, whether in-patients or out-patients were studied, and whether the figures represent the percentage of patients where mental disorder was the sole abnormality or include those with coexisting physical pathology. Lipowski (1967) concludes, largely on the basis of American studies, that $30-60 \%$ of inpatients and $50-80 \%$ of out-patients suffer psychological distress of sufficient severity to need medical help. Actual referral rates to the psychiatrist are very much lower (Table 1 ). Referral rates on the other side of the Atlantic are higher (4-13\% of inpatients) but are still well below the estimated psychiatric morbidity. We are reporting here the results of an enquiry into the reasons for the discrepancy observed between incidence and referral, and the differing rates of referral of various specialties.

\section{Methods}

In a questionnaire on attitudes to psychiatry we included a section on reasons for non-referral to a psychiatrist (Table 2). The questionnaire was a modified version of that used by Shepherd et al. (1966) in their survey of general practitioners. It was

TABLE 1. Some reports of the incidence and referral rate of psychiatric conditions in outpatients and/or in-patients seen by consultants in different specialties.

\begin{tabular}{|c|c|c|}
\hline Specialty & $\begin{array}{l}\text { Percentage of psychiatric } \\
\text { morbidity (or of } \\
\text { 'functional disorders') }\end{array}$ & $\begin{array}{l}\text { Percentage of referrals } \\
\text { to the psychiatrist }\end{array}$ \\
\hline General medicine & $\begin{array}{l}43 \cdot 5 \text { (Pemberton, 1951) } \\
\text { 38-51 (Culpan \& Davies, 1960) } \\
16 \cdot 2 \text { (Priest, 1962) } \\
26 \text { (Maclay, 1965) } \\
14 \text { (Forsyth \& Logan, 1968) }\end{array}$ & $\begin{array}{l}1 \cdot 4 \text { (Fleminger \& Mallett, 1962) } \\
3 \cdot 8 \text { (Kenyon \& Rutter, 1963) } \\
0 \cdot 4-2 \cdot 8 \text { (Bridges, Koller \& Wheeler, 1966) } \\
4 \cdot 2 \text { (Crisp, 1968) }\end{array}$ \\
\hline Neurology & 5 (Jacobs \& Russell, 1961) & 4-6 (Crisp, 1968) \\
\hline General surgery & 5-21 (Culpan \& Davies, 1960) & $\begin{array}{l}0 \cdot 16 \text { (Fleminger \& Mallett, 1962) } \\
0.37 \text { (Kenyon \& Rutter, 1963) } \\
2 \text { (Crisp, 1968) }\end{array}$ \\
\hline Gynaecology & $\begin{array}{l}38 \text { (Morris \& O'Neill, 1958) } \\
10 \text { (Munro, 1969) }\end{array}$ & $\begin{array}{l}0.18 \text { (Fleminger \& Mallett, 1962) } \\
0.59 \text { (Kenyon \& Rutter, 1963) }\end{array}$ \\
\hline All specialties & & $\begin{array}{l}0.7 \text { (Fleminger \& Mallett, 1962) } \\
1.6 \text { (MacLeod \& Walton, 1969) }\end{array}$ \\
\hline
\end{tabular}


TABLE 2. Questionnaire on reasons for not referring a patient to a psychiatrist

The following reasons have been given by doctors for NOT referring patients for psychiatric advice. Would you please indicate in the appropriate boxes, those reasons which you think have influenced your own referrals. If any reason has been particularly important in your own experience, please underline it. Please add any factors other than those mentioned, which you think have influenced you against psychiatric referral.

1. The lack of readily available psychiatric facilities

2. The patients' dislike of being referred to a psychiatrist

3. The disadvantage to patients of being labelled as mental cases

4. Psychological complaints are often made worse by medical attention

5. Psychiatric illness is largely incurable

6. A feeling that treatment of neurotic patients is the job of any doctor

7. The delay in receiving reports on patients referred to psychiatric clinic

8. Lack of satisfactory rapport between you and the psychiatrist

9. Unsatisfactory division of responsibility

10. Any others

sent to 106 consultants comprising all non-psychiatric clinicians who were on the staff of six hospitals in the area of the North East Metropolitan Regional Board. The hospitals were selected for the comprehensive nature of their clinical service and the demographic variety of the areas served by them. Eightyeight consultants completed this part of the questionnaire, giving a return of $83 \%$. The consultants included in the survey were a reasonably representative sample of clinicians working in the National Health Service. Further details on the methods used were published elsewhere (Kellett \& Mezey, 1970).

\section{Results}

Twenty-one consultants $(24 \%)$ gave no reason for non-referral. Taking all reasons together, there was no significant difference in total reasons expressed between specialties, or according to posts held and place of training, or between those with psychiatric experience and those without. Older consultantsqualifying before 1940-agreed with fewer of the reasons put forward for non-referral (Table 2) than those qualifying later $\left(120 \%: 223 \% ; \chi^{2}=15.6\right.$; $P<0.001)$ and those qualifying after 1950 gave most. Part-time National Health Service consultants gave more reasons than whole-time (204\% : $126 \%$; $\left.\chi^{2}=8.76 ; P<0.01\right)$.

The reason most frequently given was the patient's dislike of being referred, which was given by forty consultants $(45 \%)$. All categories of consultants concurred with this but there was considerable interhospital variation $\left(\chi^{2}=18.96 ; P<0.01\right)$. In one hospital thirteen out of fourteen consultants gave this as a reason for non-referral. The next most widely held reason $(21.2 \%)$ was the disadvantage to the patient of being labelled a mental case. Surgical $\stackrel{a}{c}$ specialists, including gynaecologists, more commonly $\stackrel{.}{\Rightarrow}$ felt that the patient would dislike referral $(48 \%)$, and felt less commonly that there was a real dis- 0 advantage $(19 \%)$ than medical specialists $(39 \%$ and $28 \%$, respectively) $(r=-0.906 ; \mathrm{NS})$.

Twenty per cent of consultants were influenced against referral by lack of readily available facilities. Not surprisingly, there was marked inter-hospital variation, $56 \%$ of one hospital and none of another experiencing this $\left(\chi^{2}=12.79 ; P<0.05\right)$. Eighteen $\overrightarrow{\vec{\omega}}$ per cent were affected by 'unsatisfactory rapport with $\stackrel{\omega}{\rho}$ the psychiatrist' which was related to the date of $\bar{B}$ qualification, those qualifying after 1950 experienc- 3 . ing this most frequently (post-1950 35\%; 1940-50 $23 \%$; pre-1940 8\% $\left.\chi^{2}=6.84 ; P<0.05\right)$. Only $8 \%$ نr found the division of responsibility difficult enough $\stackrel{\infty}{\infty}$ to prevent referral, and only $3 \%$ the delay in reciv- $\omega$ ing reports. When these latter four reasons $(1,7,8,9) \vec{G}$ are added to those written in which are appropriate

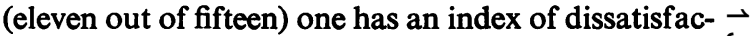
tion with the local psychiatric service. The written in reasons vary from the general ('psychiatrists are $\overparen{\Phi}$ themselves abnormal') to the particular: ('psychias $\overrightarrow{0}$ trists are poor in physical illness' and 'the psychiof $\checkmark$ trist does not treat homosexuality and impotence The majority imply a failure of the psychiatrist take over adequate care of the patient.

Using this index there is marked inter-hospital variation $\left(\chi^{2}=22.57 ; P<0.001\right)$ of which $63 \%$ is $\frac{}{\mathbb{D}}$ contributed by two hospitals who have double the average number of complaints. Those qualifying before 1940 score nearly one-fifth the index score of those qualifying after this date $\left(4 \%: 19 \% ; \chi^{2}=\right.$ 25.66; $P<0.001$ ). Part-time National Health Service consultants also found the local service less satisfactory than whole-time consultants $(15 \%: 8 \% ;$ $\chi^{2}=4.54 ; P<0.05$ ), which cannot be accounted for by the slightly greater proportion of part-time consultants at those hospitals with the greatest distrust of the local services $(72 \%: 64 \%$ ).

Only six $(7 \%)$ thought psychiatric complaints were often made worse by medical attention, and $\frac{D}{0}$ twelve thought psychiatric illness largely incurable. Of these twelve, eleven were part-time consultants, N $\left.\chi^{2}=4.38 ; P<0.05\right)$. Seventeen $(19 \%)$ consultants $N$ did not refer because they felt the treatment of $N$ neurotic patients was 'the job of any doctor', and one geriatrician did not refer many of his psychotic patients for the same reason. Here again there was an excess of part-time consultants $(25 \%: 10 \%$; $\chi^{2}=2 \cdot 88 ; P<0 \cdot 1 ;$ NS).

Reasons 3, 4, and 5, when taken together, provide an index of the belief that psychiatric referral anywhere could harm or be of no benefit to the patient. 
This belief was evenly distributed through the specialties, age groups and employment characteristics. However, there was significant interhospital variation $\left(\chi^{2}=12.05 ; P<0.05\right)$ which ran almost directly counter to the index of dissatisfaction with the local services. Thus the two hospitals with the highest number of objections to their local services, contributing about half the total $\chi^{2}$ distribution, were influenced least by reason of possible harm to the patient by psychiatric referral. Only one hospital differed from the mean in the same direction for both indices $(r=-0.495$; NS).

In a part of the questionnaire reported elsewhere (Kellett \& Mezey, 1970) consultants were asked to complete the shortened form of the Maudsley Personality Inventory (Eysenck, 1958). Seventy-four complied making $70 \%$ of the total sample, and $84 \%$ of those completing the other parts. When this part of the sample is divided into those with an extraversion score of six or less, and those with a score of seven or more, there was no significant difference in total reasons expressed, but $29 \%$ (twelve out of forty-two) of the extraverted group failed to refer on account of unsatisfactory rapport with the psychiatrist, compared with $9 \%$ (three out of thirty-two) of the less extraverted $\left(\chi^{2}=4.2 ; P<0.05\right)$. The extraverted group expressed a much greater dissatisfaction with the local service on the first index than did the less extraverted $\left(19 \%: 7 \% ; \chi^{2}=17 \cdot 23 ; P<\right.$ 0.001 ), but they did not differ on the second index of dissatisfaction with psychiatry as a whole. The groups were similarly divided into those scoring two or less on neuroticism and those scoring three to twelve ( $41 \%$ and $43 \%$ respectively). There were no significant differences for any single reason taken by itself, but on the first index the group with the higher neuroticism score was more dissatisfied $(23 \%: 10 \%$; $\left.\chi^{2}=7 \cdot 36 ; P<0.01\right)$.

\section{Discussion}

A number of reasons could account for the discrepancy between reported psychiatric morbidity and referral rates to the psychiatrist. The estimates of psychiatric morbidity may be excessive, and include many that do not require referral; the psychiatric disability may not be recognized; if recognized, it may be treated by the non-psychiatric specialist or the general practitioner; the psychiatric service may be inadequate; referral may be prevented by the attitude of the non-psychiatric consultant or the unfavourable reaction-actual or supposed-of the patient. If reports of the incidence of psychiatric morbidity represent an overestimate, those actually referred should be more severely ill than the rest. Shepherd, Davies \& Culpan (1960), comparing the sickness of those referred with random samples of medical and surgical out-patients, remark that the disorders among the latter were less urgent and included a relatively large number of minor psychological problems, but Davies (1964)-commenting on the same out-patient samples-thought that $14 \%$ needed more psychiatric treatment than a general practitioner could be expected to provide, and of those who were actually referred $(3.4 \%)$ a third were not taken on for psychiatric treatment. Kessel (1963) found that, as far as general practice was concerned, only one-tenth of the patients suitable for referral were in fact referred, and severity was not the usual criterion. Abrahams \& Golden (1963) noted the importance of the doctor-patient relationship in referrals and included identification with the patient as a cause. Thus selection by severity does not seem to account for more than part of the discrepancy.

Twenty-four per cent of the sample gave no reasons for non-referral. Seventy per cent of this group qualified before 1940, and they formed $38 \%$ of those in this qualification category compared with $13 \%$ of those qualifying later $\left(\chi^{2}=6.3 ; P<0.05\right)$. This suggests that older consultants are less likely to recognize psychiatric disorder in their patients, which agrees with the finding of Mowbray et al. (1961) that younger general practitioners identify more psychiatric patients than their older colleagues. That only $19 \%$ were prevented from referral by the belief that the treatment of neurotic illness was the job of any doctor makes recognition and treatment of psychiatric illness without referral an unlikely cause of the discrepancy. Forsyth \& Logan (1968) found a generally low cross-referral rate between various out-patient clinics, the two extreme figures being $8.9 \%$ for paediatrics and $0.8 \%$ for E.N.T. surgery. However, referrals to the psychiatrist are particularly infrequent if one takes into account the specialist's own estimate of the nature of the complaint. Thus of Priest's (1962) patients $16.2 \%$ were considered psychoneurotic - the second largest group after those suffering from alimentary disorders-but psychiatry is not among the five specialties to which most referrals were made from his general medical clinic.

Once the illness is recognized, the commonest reason against referral-occurring almost twice as commonly as any other-was the patient's dislike of being referred to a psychiatrist. The finding of Lipowski, Ramsay \& Villand (1969) that twenty out of fifty-three patients referred by general consultants failed to attend suggests a reality basis for this belief. Schwabb et al. (1966) studied the attitudes of thirty consecutive medical in-patients referred to a psychiatrist, and found twenty pleased to be referred and only four continued to be aggrieved after consultation. The large inter-hospital variation in our survey also suggests that this reason is not solely based on the attitude of the patient. 
Thirty-two $(36 \%)$ were influenced by faults in their local services, of which the most common was lack of readily available facilities $(20 \%)$. This echoes the common finding that referral rates reflect the service available. Bodkin et al. (1953) noted an increased referral rate from $4 / 10,000$ in 1949 to $73 / 10,000$ in 1951 as collaboration with a particular psychiatrist grew. With the establishment of a psychiatric unit in the general hospital serving the area, psychiatric referrals from a London borough increased by onethird in 3 years (Mezey \& Evans, 1971). Forsyth \& Logan (1968) found that $19 \%$ of new psychiatric patients had to wait more than a month before being seen, yet this is no worse than for many other specialties, $25 \%$ of medical referrals waiting this time.

It seems clear that the relationship between the psychiatrist and the other specialties was such as to prevent referrals in two hospitals of the six. Thirtytwo per cent of their consultants expressed frank lack of rapport with their psychiatrist, and it was particularly disturbing to find younger consultants most affected, since they were the most likely to refer patients. Fears about the inadequate potential of the psychiatric treatment surprisingly played little part in preventing referral, only twelve consultants thinking psychiatric illness largely incurable. This confirms the observation of Crisp (1968) that 'the clinical psychiatrist is in a position to influence the amount of such work he is called upon to do, depending on his available time and inclination'.

As mentioned in the introduction (Table 1) physicians have much higher referral rates than surgeons and gynaecologists. We could find nothing to account for this in our sample, there being little difference between physicians and surgeons in total reasons or in individual reasons, except the belief that psychiatric illness is incurable, mentioned by $19 \%$ of surgical specialists (including gynaecologists) and $9 \%$ of medical ones $\left(\chi^{2}=4.25 ; P<0.05\right)$. There may be a lower psychiatric morbidity among surgical and gynaecological patients who are usually referred with definite physical signs but few comparative studies are available. Davies (1964) estimated that eighteen out of 100 medical out-patients and ten of surgical out-patients needed to see a psychiatrist. Fleminger \& Mallett (1962) suggest that surgeons may be more tolerant of psychiatric abnormality, and the shorter stay of surgical patients gives less chance for psychiatric illness to become apparent. They found that two-thirds of surgical referrals had major psychiatric disturbance compared with a quarter of the total sample, supporting their contention that surgeons only refer the serious psychiatric problems. Kenyon \& Rutter (1963) noted that in proportion to the number referred there were five times more patients referred with disturbed ward behaviour by surgeons and gynaecologists than physicians, though more of the surgical referrals could be dealt with by advice alone. $\frac{T}{\mathbb{1}}$ Shepherd et al. (1960) found half of all surgical inpatient referrals were due to toxic and organic psychoses compared with a quarter from physicians. We could find no support for the idea that surgeons $\overline{0}$ and gynaecologists undertake themselves the treatment of psychiatric conditions not referred, only $13 \%$ of surgeons and two out of eight obstetricians not referring for this reason. However, in another part of the questionnaire (Kellett \& Mezey, 1970), twenty-one out of twenty-three surgeons agreed that the treatment of associated emotional problems was an integral part of a consultant's work. Jacobs $\stackrel{\omega}{\sigma}$ \& Russell (1961) expressed the view that every 8 specialist should endeavour to correct anxiety states 3 and minor psychiatric reactions referred to him for advice 'for it is undesirable to bring in another iv specialist'. However, the majority of patients pre- $+\infty$ senting with a primary emotional disturbance do not $\dot{\omega}$ appear to receive any psychiatric treatment during $\vec{G}$ their hospital attendance. Macy \& Allen (1933) 음 followed up for 6 years 235 patients diagnosed at the Mayo Clinic as having a neurotic illness, and found $\subseteq$ that 200 had had altogether 289 operations, with $\underset{\widetilde{D}}{2}$ little or no benefit. It is likely that many patients $\vec{\varphi}$ pass through the hospital service without recognitiog of the psychiatric nature of their illness.

Schwabb \& Brown (1968) draw attention to twa further causes for non-recognition. These are the difference of class between the patients and doctor, having found that all upper class depressives were recognized compared with only $17 \%$ of the lower class; and the acceptance of the denial of anxiety by the patient at face value.

There is no obvious explanation for the greater reluctance of part-time National Health Service consultants to refer. This group were more affected by every reason against referral except that of psychological complaints being made worse by medical attention. When whole-time consultants are considered alone the number of reasons for nonreferral is proportional to posts held $(r=+0 \cdot 32$; NS), which suggests that the more a consultant works at a particular hospital the more likely he is to refer, $\frac{D}{0}$ possibly due to better rapport. On the other hand, part-time National Health Service consultants give N most reasons for non-referral when holding only two posts.

It is clear that whilst non-recognition of psychiatric illness may account for much of the morbidity/ referral rates discrepancy, many patients are not re- $\stackrel{\circ}{\subset}$

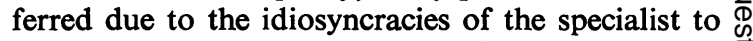
whom they have been sent in the first instance. The widespread and probably mistaken fear of the patient's dislike of referral, and the influence of the poor relationship between the psychiatrist and his 
colleagues, emphasizes the importance of improving communication between the specialties. Lipowski (1967) and Macleod \& Walton (1969) describe ways in which this can be achieved, though these may be counsels of perfection for the busy psychiatrist. There is, however, no substitute for close personal contact with non-psychiatric consultants, an ability to understand and assess relevant physical findings and to express a firm opinion in a language that all can understand. Mutual confidence is less likely to develop when contact is minimal as when clinics are held at infrequent intervals by visiting psychiatrists. The psychiatric unit in the general hospital is well placed to reduce these distortions and to enable referral practice to meet the needs of the patient.

\section{Acknowledgments}

We wish to thank the consultants of the six general hospitals (Chelmsford and Essex Hospital, Chelmsford; Essex County Hospital, Colchester; Herts and Essex Hospital, Bishops Stortford; Mile End Hospital, London, E.1; North Middlesex Hospital, London, N.18 and Whipps Cross Hospitals, London, E.11) for their co-operation.

\section{References}

Abrahams, D. \& Golden, J.S. (1963) Psychiatric consultations on a medical ward. Archives of Internal Medicine, 112, 766.

Bodkin, N.J., Gaze, R.B., Gomez, G., Howlett, M.J. \& LEIGH, D. (1953) The general practitioner and the psychiatrist: a study in co-operation. British Medical Journal, 2, 723.

Bridges, P.K., Koller, K.M. \& Wheeler, T.K. (1966) Psychiatric referrals in a general hospital. Acta psychiatria et neurologica Scandinavica, 42, 171.

CRISP, A.H. (1968) The role of the psychiatrist in the general hospital. Postgraduate Medical Journal, 44, 267.

Culpan, R.H. \& Davies, B. (1960) Psychiatric illness at a medical and a surgical out-patient clinic. Comprehensive Psychiatry, 1, 228.

DAvies, B. (1964) Psychiatric illness at general hospital clinics. Postgraduate Medical Journal, 40, 15.

EYSENCK, H.J. (1958) A short questionnaire for the measurement of the dimensions of the personality. Journal of Applied Psychology, 42, 14.

Fleminger, J.J. \& Mallett, R.L. (1962) Psychiatric referrals from medical and surgical wards. Journal of Mental Science, 108, 183.

Forsyth, G. \& Logan, R.F.L. (1968) Gateway or Dividing Line? A study of hospital out-patients in the 1960s.
Nuffield Provincial Hospitals Trust. Oxford University Press, London.

JACOBS, H. \& Russell, W. Ritchie (1961) Functional disorders. A follow-up study of out-patient diagnosis. British Medical Journal, 2, 346.

Kellett, J.M. \& Mezey, A.G. (1970) Attitudes to psychiatry in the general hospital. British Medical Journal, 4, 106.

Kenyon, F.E. \& Rutter, M.L. (1963) The psychiatrist and the general hospital. Comprehensive Psychiatry, 4, 80.

KESSEL, N. (1963) Who ought to see a psychiatrist? Lancet, i, 1092.

LIPOWSKI, Z.J. (1967) Review of consultation psychiatry and psychosomatic medicine. 2. Clinical aspects. Psychosomatic Medicine, 29, 201.

Lipowski, Z.J., Ramsay, R.A. \& Villand, H.P. (1969) Symposium. Consultation and evaluation: Psychiatric consultations in medical and surgical out-patient clinics. Canadian Psychiatric Association Journal, 14, 239.

Maclay, I. (1965) The 'functional' medical out-patient. British Journal of Psychiatry, 111, 34.

Macleod, J.G. \& WALToN, H.J. (1969) Liaison between physicians and psychiatrists in a teaching hospital. Lancet, ii, 789.

MACY, J.W. \& Allen, E.V. (1933) A justification of the diagnosis of chronic nervous exhaustion. Annals of Internal Medicine, 7, 861.

Mezey, A.G. \& Evans, E. (1971) Psychiatric in-patients and out-patients in a London borough. British Journal of Psychiatry. (In press.)

MorRIS, N. \& O'NeILL, D. (1958) Out-patient gynaecology. British Medical Journal, 1, 1038.

Mowbray, R.M., Blair, W., Jubb, L.G. \& Clarke, A. (1961) The general practitioner's attitude to psychiatry. Scottish Medical Journal, 6, 314.

Munro, A. (1969) Psychiatric illness in gynaecological outpatients: a preliminary study. British Journal of Psychiatry, $115,807$.

Pemberton, J. (1951) A sociomedical study of two hundred hospital medical patients. Lancet, i, 224.

Priest, W.M. (1962) A thousand out-patients. Lancet, ii, 1043. Shepherd, M., Cooper, B., Brown, A.C. \& Kalton, G.W. (1966) Psychiatric Illness in General Practice. Oxford University Press, London.

Shepherd, M., Davies, B. \& Culpan, R.H. (1960) Psychiatric illness in the general hospital. Acta psychiatrica et neurologica Scandinavica, 35, 518.

SchwabB, J.J. \& BRown, J. (1968) Uses and abuses of psychiatric consultation. Journal of the American Medical Association, 205, 65.

Schwabb, J.J., Clemmens, R.S., Valder, M.J. \& Raulerson, J.D. (1966) Medical patients' reactions to referring physicians after psychiatric consultations. Journal of the American Medical Association, 195, 1120. 